\title{
Existential Issues and Psychosocial Interventions in Palliative Care
}

\author{
Jae-Hon Lee, M.D., Ph.D. \\ Department of Psychiatry, School of Medicine, Gyeongsang National University Hospital, Jinju, Korea
}

\begin{abstract}
The finite nature of human existence leads many to search for meaning, which comes into sharper relief for those who are imminently facing death. Therefore, universal existential concerns such as the inevitability of death, existential isolation, loss of meaning, freedom, and dignity are inherent psychological issues in palliative care. Consequently, one of the critical challenges facing palliative care is how to address these issues effectively. This paper provides an overview of common themes of existential concerns and psychotherapeutic interventions to address existential distress among patients in palliative care.
\end{abstract}

Key Words: Existentialism, Psychotherapy, Palliative care
Received November 27, 2020

Accepted November 30, 2020

\section{Correspondence to}

Jae-Hon Lee

ORCID:

https://orcid.org/0000-0002-9490-2050

E-mail: jhlee7808@gmail.com

\section{INTRODUCTION}

The existential psychiatrist and writer Irvin Yalom [1] conceptualized four elements (death, freedom, isolation, and meaninglessness) as the basic existential concerns that human beings face [1]. These existential contemplations, which arise from our inherent limitations as human beings, are profound psychological issues that are inherently encountered by patients receiving palliative care at the end of their lives. Therefore, if such existential issues are not addressed well, patients receiving palliative care may suffer from persistent existential distress that manifests in the form of anxiety, depressive mood, or demoralization [2]. Hence, health care providers who administer palliative care must familiarize themselves with these existential concerns. They should be fully aware of the types of existential issues that patients receiving palliative care experience, how they manifest, and how health care providers can intervene in practice.

In this paper, we review the major existential issues that face patients receiving palliative care, and discuss specialized psy- chotherapeutic methods to help patients cope with these issues.

\section{EXISTENTIAL ISSUES IN PALLIATIVE CARE}

The existential issues faced by many patients receiving palliative care and their clinical manifestations are presented below [3-8].

\section{Inevitability of death}

Death, and the inevitability thereof, is an incessant and profound fear shared by all human beings. Anxiety regarding death often occurs when a person fails to adapt to the concept of death, such as continuing to refuse to accept the reality that one cannot avoid death, especially when facing the limitation of one's own life, such as moments of loss. Kierkegaard [8] used the terms "angst" or "dread" to refer to what we call "death anxiety" or what social psychologists refer to as "existential terror". "Angst" derives from the Old High German root angust, which is also the term for anger and is thought to

This is an Open Access article distributed under the terms of the Creative Commons Attribution Non-Commercial License (http://creativecommons.org/licenses/by-nc/4.0/) which permits unrestricted non-commercial use, distribution, and reproduction in any medium, provided the original work is properly cited. 
refer merely to fear or anxiety. This implies that anxiety and anger both comprise the duality of emotions related to death. Many existentialists explain "angst" in association with existential guilt, which means that one has not achieved enough in one's life-or, in other words, that one has not lived a unique life to its fullest potential. Thus, completing life tasks, making amends, forgiving and asking for forgiveness, and trying to accept the life that one has lived are all concepts related to existential issues derived from the inevitability of death. In the clinical context, symptoms are observed in the form of fears of the process of dying, or fears of the state of being dead.

\section{Existential isolation}

Existential isolation or ultimate aloneness is an existential concern that has been suggested to be an integral aspect of contemplating death. Existential isolation does not merely refer to social isolation but, rather, to the fact that we must face the ultimate challenges of our existence alone. Death is the ultimate separation from consciousness, ourselves, and our essence. Therefore, ultimately one must take the entire journey by oneself. Patients want to love someone and be loved by someone when they face this issue of existential isolation, or desire to transcend themselves, and to connect to that which is greater than themselves. In clinical practice, we can observe symptoms like feeling disconnected.

\section{Loss of meaning}

The human response to the existential concern of meaninglessness manifests through the will, search, and creation of meaning to maintain and endure one's own life. Frankl [5] proposed that the "will to meaning" - the need to find or create or experience meaning in life-is a basic motivating force of human behavior. The need to find meaning in our existence is a basic primary motivating force shaping human behavior. Meaning-making is a defining characteristic of human beings, and life has meaning and never ceases to have meaning, from the first moments of life until the last, although what is meaningful may sometimes change over time as people's circumstances change. The possibility to create or experience meaning exists throughout our lives, even in the last moment of life. If we believe that life is "meaningless", it is because we have become so demoralized that we see no possibility of creating or experiencing meaning.

Breitbart [7] highlighted the links between spiritual despair, hopelessness, and the desire for hastened death among those facing the end of life, even in the absence of overt symptoms of depression. A substantial percentage of patients who expressed a desire for hastened death were facing an existential crisis encompassing the loss of meaning, value, purpose, and hope. For these patients, it was not psychological symptoms that needed to be addressed, but instead the spiritual and $\mathrm{ex}^{-}$ istential concerns that plagued them. As discussed above, the existential distress of meaninglessness can be characterized by despair, hopelessness, and a desire for hastened death. Clinically, symptoms may manifest in the form of loss of identity.

\section{Freedom}

Freedom, the concept according to which people are free to build their lives on their own however they see fit, and become the masters of their own life, can be another reason for existential suffering. The concept of existential freedom suggests an absence of external structure imposed upon the course of our lives and a frightening existential groundlessness resulting from the idea that we are primarily responsible for our lives. The concepts of responsibility, will, and existential guilt are all derived from this ultimate freedom. In other words, it is completely up to us to create ourselves, our lives, and the meaning in our lives. The absence of an externally given destiny or meaning leaves us "groundless", and this often is experienced as anxiety and angst. Therefore, patients in palliative care could suffer from existential distress in the form of a loss of control, with accompanying symptoms such as anger at the loss of control, obsessional behavior, or indecisiveness.

\section{Dignity}

Dignity is defined as "the quality of being worthy, honored, or esteemed", and conveys the notion of the inherent respect due to patients who are preparing for death. That is, dignity refers to the notion that all human beings have an intrinsic worth. For patients in palliative care, a sense of dignity is the feeling that they are respected in spite of the psychological distress due to the illness. In the face of impending death, if one' s sense of dignity is fractured, patients in palliative care could experience feelings of degradation, shame, and embarrassment. 
The existential distress associated with dignity includes demoralization and a desire for hastened death, and manifests as symptoms such as shame and fear of being a burden in clinical practice.

\section{PSYCHOSOCIAL INTERVENTIONS IN PALLIATIVE CARE}

Psychotherapy for patients with terminal illnesses can be a profound and meaningful experience that addresses existential concerns and promotes psychological growth and development.

\section{General approaches to existential issues in palliative care}

In palliative care, psychotherapy aims to: 1) establish a bond that decreases the sense of isolation experienced with terminal illness; 2) help the patient face death with a sense of self-worth; 3) correct misconceptions about the past and the present; 4) integrate the present illness into a continuum of life experiences; 5) explore issues of separation, loss, and the unknown that lies ahead; 6) help the patient mobilize inner resources by emphasizing past strengths and supporting previously successful ways of coping; and 7) help the patient modify plans for the future, and perhaps even accept the inevitability of death.

With regard to the time to intervene, psychotherapeutic interventions are optimally initiated in palliative care before physical deterioration affects cognition and the ability to communicate, and when difficulties in psychological adjustment may be greatest. Such interventions are best delivered in the context of a multimodal approach to palliative care, where adequate attention is also given to pain and symptom relief, family distress, caregiver burden, and planning for end-of-life care [9].

\section{The psychodynamic life narrative}

The psychodynamic life narrative was described by Viederman [10] as an intervention that can be accomplished in the first few sessions of consultation with a patient in a particular crisis situation, such as severe medical illness. Through the process of talking a detailed history and then presenting the current predicament in the context of the patient's life story, past strengths and accomplishments are affirmed to increase self-esteem. This approach also creates a new perspective on dealing with illness. The medical crisis and a person's response to it are framed as a meaningful and inevitable product of his or her coping style. This psychotherapeutic intervention provides order to the patient's response at a time when he or she is otherwise struggling with feelings of hopelessness and loss of control. The intervention therefore provides patients with the opportunity to identify and reexamine their past experiences and achievements in order to find meaning, resolve old conflicts, and make amends with friends and family or take care of unfinished business [11].

\section{Meaning-centered psychotherapy}

Meaning-centered psychotherapy (MCP), a therapy method developed by Breitbart et al. [12], was initially designed to be applicable to individuals or groups of patients with advanced cancer. It was mainly inspired by Victor Frankl, and then influenced by Irvin Yalom; in particular, it was developed to address the needs of advanced cancer patients by modifying the conceptualization of Frankl that asserted the importance of meaning in human existential issues and logotherapy. Therefore, MCP states that even patients facing death can maintain and enhance a sense of meaning, thereby alleviating despair, demoralization, hopelessness, and a desire for hastened death and improving their quality of life. This therapy technique involves 1) the concept of meaning and sources of meaning; 2) cancer and meaning, and meaning in the historical context of life; 3) storytelling and the life project; 4) the limitations and finiteness of life; 5) responsibility, creativity, and deeds; 6) experiences of nature, art, and humor; and 7) goodbyes and hopes for the future. The procedure for individual patients is administered in seven once-weekly sessions, each of which last 90 minutes. The structure of each session involves processing the previous session, an introduction to the session topic, an experiential exercise, and a review of the homework assignment for the following session. MCP-palliative care (MCP$\mathrm{PC}$ ), a technique that is more appropriate for patients receiving palliative care who require one-to-one care, may be implemented more flexibly in palliative care settings than MCP. While MCP-PC can be administered across three sessions in 
its basic form, the process can be adjusted flexibly based on the patient's clinical circumstances. The first session explores the relationship between illness and meaning based on the understanding of meaning. The second session introduces sources of meaning, and the patient conducts an experiential exercise on the origin of each type of meaning. The patient then finishes the procedure during the third session by discussing his or her legacy through an experiential exercise looking for calmness. This process ultimately aims to effectively cope with existential issues through the pursuit of an enhanced sense of meaning and purpose. MCP-PC is intended to 1) promote a supportive environment for palliative care patients to explore personal issues and feelings surrounding their illness on a oneto-one therapeutic basis; 2) facilitate a greater understanding of possible sources of meaning in their lives; and 3) aid patients in their discovery and maintenance of a sense of meaning in life during illness. Although research on the clinical effects of MCP-PC, including existential issues, is mostly in the preliminary phase, multiple studies of advanced cancer patients reported that MCP helped increase spiritual well-being and a sense of meaning, while alleviating anxiety, hopelessness, the desire for a hastened death, despair, and depression. It was also observed that MCP-PC led to significantly greater improvements in spiritual well-being and a sense of meaning than supportive psychotherapy. Moreover, MCP demonstrated the possibility of lasting effects after the completion of therapy, as its therapeutic benefits showed a propensity to be reinforced, unlike patients who received supportive psychotherapy.

\section{Managing cancer and living meaningfully}

Rodin et al. [13] developed a brief, tailored supportiveexpressive psychotherapeutic intervention, referred to as Managing Cancer And Living Meaningfully (CALM) for patients with advanced cancer. On the basis of relational, attachment, and existential theory, CALM provides a therapeutic relationship and reflective space, with attention to the following four domains: 1) symptom management and communication with health care providers; 2) changes in self and relations with close others; 3) spiritual well-being and a sense of meaning and purpose; and 4) mortality and future-oriented concerns. The CALM domains are addressed for each patient in a tailored, individualized manner that allows for variation in the number of sessions and time spent on each domain on the basis of the patient's needs and health status. Each session lasts 45 60 minutes, and the procedure normally consists of four to six sessions over a period of 6 months, followed by a couple of booster sessions. The components of the treatment process of CALM include a supportive relationship, shifts in frame and flexibility, modulation and toleration of affect, encouragement of reflective functioning/mentalization, renegotiation of attachment security, the joint creation of meaning, interpretation, attention to transference and countertransference, and facing the limits and boundaries together. CALM can be delivered by a wide range of trained healthcare providers in palliative care. Research on CALM suggested that it can help patients with advanced cancer to overcome obstacles to communication and to alleviate death-related distress. Furthermore, CALM can be used to cautiously and collaboratively introduce a patient to alternative perspectives concerning the end of life, without invalidating the patient's perspective in this particularly delicate context.

\section{Dignity therapy}

Chochinov designed dignity therapy to address existential distress among terminally ill patients [14,15]. Based on the notion of dignity-conserving care, dignity therapy invites patients to address issues, memories, and reflections that they would wish to offer those they are about to leave behind. This framework emphasizes "generativity" as a significant dignity theme. Dignity themes consist of illness-related concerns, the dignityconserving repertoire, and the social dignity inventory. Illnessrelated concerns are level of independence and symptom distress. The dignity-conserving repertoire includes dignityconserving perspectives such as continuity of self, and role preservation, as well as dignity-conserving practices such as living in the moment, maintaining normalcy, and seeking spiritual comfort. Privacy boundaries, social support, care tenor, burden to others, and aftermath concerns are the components of the social dignity inventory. Sessions are tape-recorded, transcribed, and edited, with the therapist helping the patient to organize the dignity psychotherapy question protocol. The transcript is returned to the patient within one to two days and it is usually left for the family as part of the patient's personal legacy. The creation of a tangible product that will live beyond 
the patient acknowledges the importance of generativity as a salient dignity issue, while strengthening the patient's sense of purpose, meaning, and worth. Dignity therapy was reported to be significantly more effective than client-centered care in improving spiritual well-being and heightening patients' sense of dignity, purpose, and meaning. The symptoms of depression and suffering were correspondingly reduced.

\section{CONCLUSION}

The primary goal of palliative care is to improve the quality of life for patients at the end of life, and effective psychological interventions based on an understanding of existential concerns is an integral component of facilitating that objective. Good palliative care should acknowledge the innate existential nature of distress that accompanies the experience of dying. Various existential issues including the inevitability of death, existential isolation, loss of meaning, freedom, and dignity can manifest in clinical practice as symptoms like fear of the process of $\mathrm{dy}^{-}$ ing, feeling disconnected, loss of identity, meaninglessness, desire for a hastened death, loss of control, and demoralization. There are psychotherapeutic techniques to address these issues, including Psychodynamic Life Narrative, MCP, CALM therapy, and Dignity Therapy. These techniques are effective for addressing existential issues to improve patients' quality of life compared to previous classic psychotherapeutic interventions. Healthcare providers in palliative care should apply these therapies appropriately to promote the search for meaning and to affirm the dignity of persons nearing death.

\section{CONFLICT OF INTEREST}

No potential conflict of interest relevant to this article was reported.

\section{REFERENCES}

1. Yalom ID. Existential psychotherapy. New York:Basic Books;c1980.

2. Kissane DW, Poppito S. Death and dying. In: Blumenfield M, Strain JJ, eds. Psychosomatic medicine. Philadelphia:Lippincott Williams \& Wilkins;c2006. p. 671-94.

3. FrankI VE. Man's search for meaning. 4th ed. Boston, MA:Beacon;c1959.

4. FrankI VE. Man's search for ultimate meaning. New York:Plenum;1997.

5. FrankI VE. The will to meaning: foundations and applications of logotherapy. New York:New American Library;c1988.

6. Chochinov HM. Dying, dignity, and new horizons in palliative end-of-life care. CA Cancer J Clin 2006;56:84-103; quiz 104-5.

7. Breitbart W. Meaning-centered psychotherapy in the cancer setting finding meaning and hope in the face of suffering. New York, NY:Oxford University Press;2017.

8. Kierkegaard S, Hong HV, Hong EH. Fear and trembling ; Repetition. Princeton, NJ:Princeton University Press;1983.

9. Rodin G. Individual psychotherapy for the patient with advanced disease. In: Chochinov HM, Breitbart W, eds. Handbook of psychiatry in palliative medicine. 2nd ed. New York, NY: Oxford University Press;2009. p. 443-53.

10. Viederman M. The psychodynamic life narrative: a psychotherapeutic intervention useful in crisis situation. Psychiatry 1983;46:236-46.

11. Viederman M. The supportive relationship, the psychodynamic life narrative, and the dying patient. In: Chochinov HM, Breitbart W, eds. Handbook of psychiatry in palliative medicine. 2nd ed. New York, NY:Oxford University Press;2000. p. 215-23.

12. Breitbart W, Rosenfeld B, Pessin H, Applebaum A, Kulikowski J, Lichtenthal WG. Meaning-centered group psychotherapy: an effective intervention for improving psychological well-being in patients with advanced cancer. J Clin Oncol 2015;33:749 - 54.

13. Rodin G, Lo C, Rydall A, Shnall J, Malfitano C, Chiu A, et al. Managing Cancer and Living Meaningfully (CALM): A Randomized Controlled Trial of a Psychological Intervention for Patients With Advanced Cancer. J Clin Oncol 2018;36:2422 - 32.

14. Chochinov HM, Hack T, Hassard T, Kristjanson L, McClement S, Harlos M. Dignity therapy: a novel psychotherapeutic intervention for patients near the end of life. J Clin Oncol 2005;23:5520-5.

15. Chichinov HM. Dignity-conserving care-a new model for palliative are: helping the patient feel valued. JAMA 2002;287:2253-60. 